\title{
Antibacterial effects of Saponaria officinalis extracts against avian pathogenic Escherichia coli (APEC)
}

\author{
Abdolreza Nabinejad \\ Isfahan Research Center for Agriculture (ABRII), Isfahan, Iran.
}

Accepted 8 May, 2013

\begin{abstract}
In current study using Saponaria officinalis (Related to Caryophyllaceae family) hydroalcoholic extracts for in vitro growth inhibition of an avian isolated fatal Escherichia coli (isolated from coli CRDcomplex carcasses) were reported. The disc diffusion method was used for evaluation of the antibacterial effects of Saponaria extracts in comparison to some routine antibiotics. Minimum inhibitory concentration (MIC) of Saponaria extracts against avian pathogenic E. coli, APEC, using tube dilution technique was studied. In titration technique for MIC, the concentration of the extracts was estimated in $v / v$ in Dimethyle sulfoxide (DMSO) as inert solvent. For minimum bacterial concentration (MBC) studies $0.1 \mathrm{ml}$ of MIC titer beside, a tube before and after, MIC titer were used for cultivation on Muller Hinton agar. Based on the results, the zones of inhibition for 10, 15 and $20 \mu l$ of Saponaria disks were 16, 18 and $19 \mathrm{~mm}$, respectively, and the zones of inhibition diameter for antibiotic disks of Fosbac (Fos), Oxytetracycline (Oxy) and Danofloxacin (Dfx) were 15, 0 and $14 \mathrm{~mm}$, respectively. In MIC technique, it is oriented that the concentration of 1/80 inhibits APEC growth but for MBC, the bacterial growth on Muller Hinton agar was not stopped. The present study has revealed that saponin extract from $S$. officinalis has useful antibacterial effects.
\end{abstract}

Key words: Antibacterial effects, coli chronic respiratory disease (CRD), Escherichia coli, minimum bacterial concentration (MBC), minimum inhibitory concentration (MIC), Saponaria officinalis, Saponin.

\section{INTRODUCTION}

Escherichia coli is one of the common microbial flora of gastrointestinal tract of poultry and human being including other animals but may become pathogenic to both (Akond et al., 2009). Enteritis caused by E. coli (colibacilliosis) is an important disease in the poultry industry because of increased mortality and decreased performance (Barnes et al., 2003). Avian pathogenic $E$. coli (APEC) is causative agent of avian colibacillosis (Moon et al., 2006). Avian colibacillosis occurs most commonly in 3 to 12-week-old broiler chickens, turkeys and ducks and is characterized by extra intestinal disease, principally respiratory or systemic infections (Moon et al., 2006). This disease is responsible for loss in productivity and approximately $20 \%$ mortality in poultry flocks, contributing to substantial economic losses in many parts of the world. In humans, pathogenic E. coli can cause several diseases including urinary tract infections, septicemia, and neonatal meningitis (Furtula et al., 2010).

Antibiotics are commonly used in disease treatment. Antibiotic usage has an important effect on the emergence of antimicrobial resistance in bacteria 
(Furtula et al., 2010). An increase in resistance to antibiotics by many microbes has been observed within the last decade to the extent that microbes resistant to every known antibiotic have been identified (Hassan et al., 2008). E. coli resistance against many known antibiotics has also been reported (Johnson et al., 2006). One suspected source of drug-resistant $E$. coli in humans is the use of antimicrobial drugs in agriculture food production (Collignon et al., 2006).

Awareness of potential problems associated with antimicrobial resistance evolving from the use of antibiotics as feed additives has focused research efforts to identify alternatives for controlling infections and increasing performance in animal production (Vicente et al., 2007). Researchers worldwide are working to develop antibiotic alternative products such as probiotics, prebiotics (Higgins et al., 2005b, 2007) organic acids (Van Immerseel et al., 2006) and medicinal herbs (Arab et al., 2006). Original candidate chemical structures for many pharmaceutical compounds used to promote human health originated from chemicals found in plant extracts (Arab et al., 2006). Among these plant compounds are saponins which have several beneficial effects such as antibacterial and antiprotozoal activities (Avato et al., 2006).

Saponins are glycoside compounds distributed in both wild and cultivated plants (Shimoyamada et al., 1990), lower marine animals and some bacteria (Riguera, 1997). Saponins acquired their name from the soapwort plant (Saponaria root) which was used as soap (Hassan et al., 2008). Saponins are synthesized by a common metabolic pathway starting from acetyl coenzyme A (Hassan et al., 2008). Mevalonic acid and then squalene are the intermediary products for both triterpenoidal and steroidal saponins (Hassan et al., 2008).

Saponins have many biological properties, among them are hemolytic (Woldemichael et al., 2001), antibacterial (Hassan et al., 2007) and antiprotozoal activities (Mshvildadze et al., 2000). Many saponins are antimicrobial and considered as a part of plants' defense systems (Hassan et al., 2008). Not all saponins have antibacterial activity (Hassan et al., 2008). Antibacterial activities of saponins differ according to type of the bacteria (Hassan et al., 2008). Its medicinal uses include it being used as an antiscrophulatic, cholagogue, depurative, diaphoretic, mildly diuretic, expectorant, purgative and tonic (sengul et al., 2011).

Saponins from various sources differ in their biological activity due to their different chemical structures and extraction procedure (Sen et al., 1998b). Extraction methods and fat content have important effects on the antibacterial activity of the resultant plant extracts (Hassan et al., 2008). The previous information indicated that new antibiotic and coccidiostats must be continually developed to overcome increasing resistance to chemical drugs in bacteria and parasites (Yadav et al., 2001).

Therefore the present study was carried out to investigate the antibacterial effects of Saponaria officinalis extracts against avian pathogenic E. coli (APEC).

\section{MATERIALS AND METHODS}

\section{Plant materials}

The seeds of $S$. officinalis (related to Caryophyllaceae) were collected from Isfahan research centre for agriculture, Amir Hamzeh city, Isfahan, Iran. The samples were then air dried in an oven and ground to form a fine powder using a mortar and pestle. The resulting powder was then kept at room temperature prior to extraction for analyzing its antibacterial activity.

\section{Determination of antibacterial activity}

\section{Preparation of test micro-organisms}

Strains of avian pathogenic E. coli, APEC, (isolated from coli CRDcomplex carcasses) were used as test organisms. The APEC were confirmed via in vitro (bacteriological and biochemical tests) and in vivo (by oral inoculation to 3 weeks old isolated chicks) tests.

\section{Test organisms}

Hydroalcoholic extracts of the samples were tested against APEC to analyze the antimicrobial activity of the extracts. The bacteria, APEC, were propagated in Muller Hinton broth and incubated for 6 hrs at $25^{\circ} \mathrm{C}$ adjusted to Mc Farland standard. The identity of the bacteria used in this study was confirmed using the common bacteriologic and biochemical tests.

\section{Extraction of plant material for antibacterial activity}

Hydroalcoholic extract of $S$. officinalis was obtained by the percolation method. In summary, $10 \mathrm{~g}$ of powdered dried seed was put into percolator and $100 \mathrm{ml}$ of $80 \%$ methanol was added to the powder for two days. Then the extract was saved in $4^{\circ} \mathrm{C}$ dark tube. Some filter papers were punched, sterilized and used as disk for preparation of the saponin disks as 10,15 and $20 \mu$ land incubated for $15 \mathrm{~h}$ at $37^{\circ} \mathrm{C}$ for drying. The pure prepared extracts was used for titration using in tube dilution techniques in MIC and MBC tests.

\section{Disc-diffusion assay}

The extracts were dissolved in the same solvent (methanol and water) and afterwards sterilized by filtering through $0.45 \mu \mathrm{m}$ Millipore filters. Antibacterial tests were then carried out by disc diffusion using $0.1 \mathrm{~mL}$ of suspension containing $108 \mathrm{CFU} / \mathrm{ml}$ of bacteria spread on Muller Hinton agar medium for antibiogram tests. The discs (6 mm in diameter) were impregnated with 10,15 and $20 \mu \mathrm{l}$ of Saponaria extracts and placed on the inoculated agar. Negative controls were prepared using the same solvents employed to dissolve the plant extracts. Oxytetracycline, Danofloxacin and Fosbac were used as positive reference standards to determine the sensitivity of avian pathogenic $E$. coli, APEC. The inoculated plates were incubated for $24 \mathrm{~h}$ at $37^{\circ} \mathrm{C}$. The antibacterial activity was evaluated by measuring the zone of inhibition against the test organisms. Each assay in the experiment was repeated in 3 times. 


\section{Minimum inhibitory concentration (MIC) and minimum bacterial concentration (MBC) technique}

For minimal inhibitory concentration (MIC), $1 / 5$ in V/V extracts diluted by Dimethyle sulfoxide (DMSO) as inert solvent, and a serial dilution prepared using 2 fold dilution, $0.5 \mathrm{ml}$ of each of final dilutions added to the same sterile tube as test tubes, also one tube used for positive control and another one used as negative control, a $0.5 \mathrm{ml}$ of Muller Hinton broth were added to each of test and control tubes ,therefore the final titter of saponaria extracts were $1 / 10,1 / 20,1 / 40,1 / 80,1 / 160,1 / 320,1 / 640$, and $1 / 1280$.

For MIC tests, a $0.05 \mathrm{ml}$ of APEC logarithmic phase suspension containing $10^{8} \mathrm{CFU}$ of bacteria were added to the test tubes, and in positive control no extracts was added and in negative control no bacteria was added. All of 10 tubes were incubated overnight in the $37^{\circ} \mathrm{C}$ and then regarding to the turbidity of the broth media and bacterial growth, the MIC titter were estimated and recorded. Each assay in the experiment were repeated 3 times.

For minimum bactericidal concentration (MBC) studies, $0.1 \mathrm{ml}$ of MIC titer beside, a tube before and after, MIC titer was used for cultivation on Muller Hinton agar and tubes were incubated $24 \mathrm{~h}$ in the $37^{\circ} \mathrm{C}$ for bacterial growth and colony formation.

\section{RESULTS}

In disc diffusion method, the hydroalcoholic extracts of $S$. officinalis exhibited antibacterial activity against investigated microorganisms with a 16, 18 and $19 \mathrm{~mm}$ zone of inhibition for 10, 15 and $20 \mu \mathrm{l}$ of Saponaria disks respectively and the zones of inhibition diameter for antibiotic disks of Fos, Oxy and Dfx were $15 \mathrm{~mm}, 0 \mathrm{~mm}$ and $14 \mathrm{~mm}$, respectively.

In MIC technique, it is oriented that bacterial growing start from the concentration of $1 / 80$, so minimal inhibitory concentration were known as 1/80 which inhibited APEC growth in the test tubes of M.H. broth.

In MBC technique, the bacterial growth on M.H. agar was not stopped, it meant that saponaria extracts could not destroy the APEC and had not bactericidal effects. When the activity of the plant extract was compared with that of the standard antibiotics, Oxytetracycline, Danofloxacin and Fosbac used in disk diffusion method, it was observed that Saponaria extract compared favourably with those of these standard antibiotics. Thus improvement on such extract by pharmaceutical industry to produce antibacterial drug of natural source will go a long way in healthcare delivery. The present study has revealed that saponin extract from $S$. officinalis has useful antibacterial properties.

\section{DISCUSSION}

Sensitivity of bacteria to saponins has often been reported (Barile et al., 2007; Mandal et al., 2005; Avato et al., 2006). Saponins have also been reported to have antimicrobial activity (Soetan et al., 2006; Avato et al., 2006; Edewor et al., 2009; Hassan et al., 2010). It is possible to conclude that the aerial parts of $S$. officinalis exhibit antibacterial activity against a number of bacteria
(Sengul et al., 2011). This is surprising because the Gram-negative bacteria and fungi have been shown to be more resistant to antibiotics (Soetan et al., 2006). Based on the result of this study it can be said that $S$. officinalis is an effective antibacterial plant that will be a good source for finding the antibiotic alternative agents in order to treat and control infections. This finding is consistent with previous published reports that specific saponins have great potential as antimicrobial compounds against microorganisms. It is interesting that Saponaria extracts were active against avian pathogenic E. coli (APEC), which has been implicated in several infections of human and animals.

\section{ACKNOWLEDGMENTS}

The author sincerely thank Dr. Zeinally for his valuable support and also, Mrs Shirian for her cooperation in the editing.

\section{REFERENCES}

Akond MA, Alam S, Hassan SMR, Shirin M (2009). Antibiotic resistance of Escherichia coli isolated from poultry and poultry environment of Bangladesh. Internet J. Food Safety 11:19-23.

Arab HA, Rahbari S, Rassouli A, Moslemi MH, Khosravirad F (2006). Determination of artemisinin in Artemisia sieberi and anticoccidial effects of the plant extract in broiler chickens. Trop. Anim. Heal. Prod. 38:497-503.

Avato P, Bucci R, Tava A, Vitali C, Rosato A, Bialy Z, Jurzysta M (2006). Antimicrobial activity of saponins from Medicago spp. Structure-activity relationship. Phytother. Res. 20:454-457.

Barile E, Bonanomi G, Antignani V, Zolfaghari B, Sajjadi SE, Scala F, Lanzotti V (2007). Saponins from Allium minutiflorum with antifungal activity. Phytochemistry 68:596-603.

Barnes HJ, Vaillancourt JP, Gross WB (2003). Colibacillosis. In: Diseases of Poultry. 11th ed., lowa State University Press, Ames, IA, USA.

Collignon PJ, Wilkinson IJ, Gilbert GL, Grayson ML, Whitby RM (2006). Health care-associated Staphylococcus aureus bloodstream infections: A clinical quality indicator for all hospitals. Med. J. Aust. 17;184(8):404-6.

Edewor TI, Ibikunle GJ, Usman LA (2009). Phytotoxic and antimicrobial screening of Saponin isolated from ethanolic leaf extract of xylopia aethipioca. Sci. Focus 14:507-512.

Furtula V, Farrell EG, Diarrassouba F, Rempel H, Pritchard J, Diarra MS (2010). Veterinary pharmaceuticals and antibiotic resistance of Escherichia coli isolates in poultry litter from commercial farms and controlled feeding trials. Poult. Sci. 89:180-188.

Hassan SM, Carey JB, Hume ME, Byrd JA, Bailey CA, Cartwright AL (2008). Antimicrobial activities of saponin-rich guar meal extract. Poult. Sci. pp 1-179.

Hassan SM, Gutierrez O, Haq AU, Byrd JA, Bailey CA, Cartwright AL (2007). Saponin-rich extracts from quillaja, yucca, soybean, and guar differ in antimicrobial and hemolytic activities. Poult. Sci. 86:121 (Abstr.).

Hassan SM, Haq AU, Byrd JA, Berhow MA, Cartwright AL, Bailey CA (2010). Haemolytic and antimicrobial activities of saponin-rich extracts from guar meal. Food Chem. 119: 600-605.

Higgins JP, Higgins SE, Salvador V, Wolfenden AD, Tellez G, Hargis BM (2007). Temporal effects of lactic acid bacteria probiotic culture on Salmonella in neonatal broilers. Poult. Sci. 86:1662-1666.

Higgins SE, Torres-Rodriguez A, Vicente JL, Sartor CD, Pixley CM, Nava GM, Tellez G, Barton JT, Hargis BM (2005b). Evaluation of 
intervention strategies for idiopathic diarrhea in commercial turkey brooding houses. J. Appl. Poult. Res. 14:345-348.

Johnson JR, Kuskowski MA, Menard M, Gajewski A, Xercavins M, Garau J (2006). Similarity of human and chicken-source Escherichia coli isolates in relation to ciprofloxacin resistance status. J. Infect. Dis. 94:71-78.

Mandal P, Sinha Babu SP, Mandal NC (2005). Antimicrobial activity of saponins from Acacia auriculiformis. Fitoterapia 76:462-465.

Moon BM, Won GY, Choi YY, Jin JK, Oh IG, Park JH, Eo SK, Lee JH (2006). Isolation and characteristics of avian pathogenic Escherichia coli from birds associated with colibacillosis. Chulalongkorn Uni. Fac. Vet. Sci., Bangkok, Thailand. pp. 26-29.

Mshvildadze V, Favel A, Delmas F, Elias R, Faure R, Decanosidze G, Kemertelidze E, Balansard G (2000). Antifungal and antiprotozoal activities of saponins from Hedera colchica. Pharmazie 55:325-326.

Riguera R (1997). Isolating bioactive compounds from marine organisms. J. Marine Biotechnol. 5:187-193.

Sengul M, Ercisli S, Yildiz H, Gungor N, Kavaz A, Çetin B (2011). Antioxidant, antimicrobial activity and total phenolic content within the aerial parts of Artemisia absinthum, Artemisia santonicum and Saponaria officinalis. Iran. J. Pharm. Res. 10(1):49-56

Sen S, Makkar HPS, Muetzel S, Becker K (1998b). Effect of Quillaja saponaria saponins and yucca schidigera plant extract on growth of Escherichia coli. Lett. Appl. Microbiol. 27:35-38.

Shimoyamada M, Kudo S, Okubo K, Yamauchi F, Harada K (1990). Distribution of saponin constituents in some varieties of soybean plant. Agric. Biol. Chem. 54:77-81.

Soetan KO, Oyekunle MA, Aiyelaagbe OO, Fafunso MA (2006). Evaluation of the antimicrobial activity of saponins extract of Sorghum Bicolor L. Moench. Afr. J. Biotechnol. 5:2405-2407.
Van Immerseel F, Russell JB, Flythe MD, Gantois I, Timbermont L, Pasmans F, Haesebrouck F, Ducatelle R (2006). The use of organic acids to combat Salmonella in poultry: a mechanistic explanation of the efficacy. Avian. Pathol. 35:182-188.

Vicente JL, Avina L, Torres-Rodriguez A, Hargis B, Tellez G (2007). Effect of a Lactobacillus spp. based probiotic culture product on broiler chicks performance under commercial conditions. Int. J. Poult. Sci. 6:154-156.

Woldemichael GM, Wink M (2001). Identification and biological activities of triterpenoid saponins from Chenopodium quinoa. J. Agric. Food Chem. 49:2327-2332.

Yadav A, Gupta SK (2001). Study of resistance against some ionophores in Eimeria tenella Weld isolates. Vet. Parasitol. 102:6975. 